\title{
Levels of circulating and urinary oestrogens during pregnancy in the marmoset monkey (Callithrix jacchus)
}

\author{
J. K. Hodges, Heather Brand, Cilla Henderson and R. W. Kelly*
}

Department of Reproduction, Institute of Zoology, Regent's Park, London NWI 4RY, and

*M.R.C. Reproductive Biology Unit, Centre for Reproductive Biology, 37 Chalmers Street, Edinburgh EH3 9EW, U.K.

\begin{abstract}
Summary. The levels of immunoreactive oestrone, oestradiol-17 $\beta$ and oestriol in plasma and urine were measured during early, mid- and late pregnancy in the marmoset monkey. In plasma, unconjugated oestrone remained $<2 \%$ of total (conjugated plus unconjugated) oestrone throughout gestation, whereas unconjugated oestradiol- $17 \beta$ increased from $3 \%$ of the total value in early and mid-pregnancy to $35 \%$ in late pregnancy. The reversal in the unconjugated oestrone :oestradiol- $17 \beta$ concentration ratio from early $(12: 1)$ to late $(0 \cdot 15: 1)$ pregnancy occurred despite the continuing predominance of oestrone in terms of total hormone. Total oestriol was measurable but in relatively low concentrations. Oestradiol conjugate was the predominant urinary oestrogen metabolite measured at each stage of pregnancy. The pattern of urinary oestrone and oestradiol- $17 \beta$ reflected plasma levels of total hormone, rather than unconjugated hormone, showing no further increase after mid-pregnancy. In contrast, oestriol increased throughout pregnancy and to a proportionately greater extent than oestrone or oestradiol- $17 \beta$, but at lower absolute levels.

High-pressure liquid chromatography of urine extract indicated the presence of considerable amounts of oestrogen immunoreactivity not accounted for by oestrone, oestradiol-17 $\beta$ and oestriol and with a retention time similar to that of $16 \alpha$ hydroxyoestrone. Gas chromatography and mass spectroscopy provided further evidence to suggest that $16 \alpha$-hydroxyoestrone is an abundant urinary oestrogen metabolite during pregnancy in the marmoset monkey.
\end{abstract}

\section{Introduction}

Studies on the production and excretion of oestrogens during pregnancy in non-human primates have concentrated on Old World monkeys and apes and only a few comparable data exist for New World species (Ryan \& Hopper, 1974). Peripheral concentrations of unconjugated oestrone and oestradiol (Chambers \& Hearn, 1979) and urinary total oestrogen values (Lunn, 1978) have been measured throughout gestation in common marmosets. Shackleton (1974), using gas chromatography-mass spectrometry, identified oestradiol- $17 \beta$ as the most abundant urinary oestrogen metabolite in late gestation. The concentrations of urinary total immunoreactive oestrogen during pregnancy in a capuchin monkey have recently been described by Czekala, Hodges \& Lasley (1981). Immunological measurement of individual urinary oestrogen metabolites, however, has not been reported and there have been no attempts to relate circulating and urinary oestrogens in any species of New World primate. The present paper considers both of these aspects in an initial effort 
to characterize some of the basic features of oestrogen metabolism during pregnancy in the common marmoset.

\section{Materials and Methods}

The animals were sexually mature female marmoset monkeys maintained in the laboratory primate colony of the Institute of Zoology for at least 1 year. The body weight of the monkeys ranged from 0.3 to $0.4 \mathrm{~kg}$. The marmosets were kept in male-female pairs or in family groups and were supplied with food once daily and water ad libitum. Rooms were maintained within a temperature range of $24-27^{\circ} \mathrm{C}$ and received natural daylight with additional illumination between $08: 00$ and $20: 00 \mathrm{~h}$.

\section{Sample collection}

Blood samples $(0.8 \mathrm{ml})$ were taken from the femoral vein into a heparinized $1.0 \mathrm{ml}$ syringe and placed immediately on ice. Animals were not sedated before venepuncture. The blood was centrifuged at $500 \mathrm{~g}$ for $20 \mathrm{~min}$ and the plasma stored at $-20^{\circ} \mathrm{C}$ until assayed. Urine samples to match the blood samples were collected in aluminium metabolism cages $(20 \mathrm{~cm}$ in diameter) fitted with a plastic funnel lined with clean polythene. During the period of collection (which varied for individuals, but was usually $<3 \mathrm{~h}$ ), animals were provided with water from drip-free bottles, but were not given food. The urine $(1-3 \mathrm{ml})$ was collected following blood sampling and was aspirated from a polythene sheet using a Pasteur pipette, centrifuged at $400 \mathrm{~g}$ for $10 \mathrm{~min}$ and stored at $-20^{\circ} \mathrm{C}$ until assayed. Care was taken to minimize fecal contamination of the urine although the possibility of some hydrolysis of oestrogen conjugates occurring during the collection period cannot be excluded.

Sample collection was scheduled for the stages of pregnancy shown in Tables 2 and 3. Postpartum females were bled 3 times weekly and progesterone concentrations were measured to detect ovulation. Elevated progesterone levels for 4 weeks after the initial rise and an increase in uterine diameter were used to indicate pregnancy. A rise in progesterone to $>10 \mathrm{ng} / \mathrm{ml}$ was considered to be Day 1 of pregnancy (Chambers \& Hearn, 1979). In the early stages of pregnancy (Tables 2 and 3) diagnosis of pregnancy was made retrospectively.

\section{Hormone assays}

Total (i.e. conjugated plus unconjugated) oestrogen determinations for oestrone, oestradiol-17 $\beta$ and oestriol were carried out by incorporating enzyme hydrolysis before extraction. Glucuronidase sulphatase (Sigma Chemical Co., Poole, Dorset: glucuronidase activity 95100 Fishman units/ml: arylsulphatase activity $2920 \mu \mathrm{m}$ units $/ \mathrm{ml}$ ) was diluted with phosphate buffer (pH 5.0) to give a concentration of 476 Fishman units $/ 0.2 \mathrm{ml}$ which was then added to $0.1 \mathrm{ml}$ urine or plasma, mixed gently and incubated at $37^{\circ} \mathrm{C}$ for $20 \mathrm{~h}$. Unconjugated oestrogen measurements were made without this step. Several aliquants of each sample were prepared before chromatographic separation.

Tritiated steroid (1500 c.p.m. each of oestrone and oestradiol, sp. act. $92 \mathrm{Ci} / \mathrm{mmol}$ and 100 $\mathrm{Ci} / \mathrm{mmol}$, respectively; or 1500 c.p.m. oestriol, sp. act. $114 \mathrm{Ci} / \mathrm{mmol}$ ) (Radiochemical Centre, Amersham, U.K.) was added to separate aliquants before extraction with 10 volumes of freshly distilled diethyl ether. After evaporation with nitrogen, the residue was reconstituted in $1.0 \mathrm{ml}$ isooctane (oestrone and oestradiol) or $10 \%$ ethyl acetate in isooctane (oestriol) and subjected to celite column chromatography according to the method of Anderson, Hopper, Lasley \& Yen (1976) as described by Hodges et al. (1981). Solvents were obtained from Fisons Scientific Apparatus, Loughborough, England. Oestrone and oestradiol were eluted from an ethylene glycol :celite (1:2 $\mathrm{v} / \mathrm{w}$ ) column with $3.5 \mathrm{ml}$ of $15 \%$ and $40 \%$ ethyl acetate in iso-octane, respectively (Abraham, Tulchinsky \& Korenman, 1970). Oestriol was eluted from a water : celite $(1: 3 \mathrm{v} / \mathrm{w})$ column with 5 $\mathrm{ml} \mathrm{100 \%}$ ethyl acetate (Tulchinsky \& Abraham, 1971). 
The procedure for radioimmunoassay was a slight modification of the method used for the World Health Organization Matched Reagent Program. In brief, the protocol was as follows. After celite chromatography, samples were dried under nitrogen and reconstituted in $1.0 \mathrm{ml}$ phosphatesaline buffer ( $\mathrm{pH} \mathrm{7.2)} \mathrm{containing} \mathrm{gelatin.} \mathrm{Duplicate} \mathrm{aliquants} \mathrm{were} \mathrm{taken} \mathrm{to} \mathrm{assay} \mathrm{and} \mathrm{the} \mathrm{volume}$ made up to $0.5 \mathrm{ml}$ with buffer. One additional aliquant was taken for recovery determination. Standard curves were run in triplicate over the range $6.25-400 \mathrm{pg} /$ tube (doubling dilutions). Antiserum and tracer $\left(0 \cdot 1 \mathrm{ml}\right.$ each) were added and the contents incubated at $4^{\circ} \mathrm{C}$ for $20-24 \mathrm{~h}$. Separation of bound and unbound fractions was achieved by the addition of $0.2 \mathrm{ml}$ ice-cold dextran-coated charcoal suspension $(0.6 \%$ charcoal and $0.06 \%$ dextran in assay buffer $)$, incubation at $4^{\circ} \mathrm{C}$ for $15 \mathrm{~min}$ and centrifugation at $500 \mathrm{~g}$ and $4^{\circ} \mathrm{C}$ for $10 \mathrm{~min}$. Supernatants were decanted into mini-scintillation vials containing $2.0 \mathrm{ml}$ scintillant (Pico-Fluor: Packard Instruments Ltd, Caversham, U.K.) and counted for $3 \mathrm{~min}$ in a scintillation spectrometer (Model 3255 Packard Tricarb).

Oestradiol antiserum (supplied by W.H.O.) was raised against oestradiol-3-carboxymethyl oxime-bovine serum albumin (BSA) in a rabbit. Cross-reactivities (determined at the level of 50\% displacement of binding) were $1.7 \%$ for oestrone, $1.0 \%$ for oestriol and $<0.01 \%$ for testosterone and cortisol. Dilution was adjusted to bind $30 \%$ of the labelled steroid in the absence of competing unlabelled steroid. Antisera to oestrone and oestriol (Steranti Research Ltd) were raised in rabbits against oestrone- and oestriol-6-carboxymethyl oxime-BSA respectively. Measured crossreactivities for the oestrone antiserum were $0.1 \%$ for oestradiol- $17 \beta, 0.06 \%$ for oestradiol-17 $\alpha$, $0.01 \%$ for oestriol and $<0.02 \%$ for tested $\mathrm{C} 19$ and $\mathrm{C} 21$ steroids; those for the oestriol antiserum were $105 \%$ for oestriol- 6 -oxo, $0.05 \%$ for oestradiol- $17 \beta, 0.001 \%$ for oestrone and $<0.001 \%$ for tested $\mathrm{C} 19$ and C21 steroids. Dilutions of the oestrone and oestriol antisera were adjusted to bind approximately $23 \%$ and $28 \%$ respectively of labelled steroid in the absence of competing unlabelled steroid.

Procedural losses were monitored individually. The mean \pm s.e.m. recovery values for each assay are given in Table 1. The sensititivy of each assay, calculated from the mass of hormone required to suppress the binding of the labelled hormone to $90 \%$ of the binding achieved in the absence of unlabelled hormone is also shown in Table 1. Buffer blanks, with and without hydrolysis enzyme, which were extracted and run through celite in each assay, gave values less than the sensitivities of the assays. Interassay precision was expressed as the coefficient of variation for replicate determinations of a low and high value plasma pool (Table 1).

Validation of the measurement of each hormone was achieved by performing celite column cochromatography and comparing the profile of immunoreactivity with that of pure tritiated steroid

Table 1. The recovery, assay sensitivity and interassay precision for the oestrogens measured in marmoset plasma and urine in this study

\begin{tabular}{|c|c|c|c|c|c|c|}
\hline & \multirow[b]{3}{*}{ Recovery* } & \multicolumn{3}{|c|}{ Sensitivity } & \multirow{2}{*}{\multicolumn{2}{|c|}{ Interassay precision $\ddagger$}} \\
\hline & & & Plasmat & & & \\
\hline & & $\mathrm{pg} /$ tube* & (ng/ml) & (ng/mg Cr) & High pool & Low pool \\
\hline Oestrone & $\underset{(62) \S}{72 \cdot 6 \pm 1 \cdot 7}$ & $5 \cdot 7 \underset{(5) \pi}{ \pm} 0.3$ & $0 \cdot 14$ & 130 & $\begin{array}{l}11 \cdot 2 \\
(5) 9\end{array}$ & 8.6 \\
\hline Oestradiol & ${ }_{(62)}^{76 \cdot 7}+1 \cdot 8$ & $6 \cdot 0 \pm \frac{ \pm}{(5)} 0 \cdot 1$ & $0 \cdot 14$ & 130 & $\begin{array}{l}5 \cdot 6 \\
(5)\end{array}$ & $12 \cdot 1$ \\
\hline Oestriol & $\underset{(26)}{79 \cdot 8 \pm 2 \cdot 0}$ & $3 \cdot 9 \frac{ \pm}{(3)} 0.2$ & $0 \cdot 10$ & 11 & $\begin{array}{c}10 \cdot 2 \\
(3)\end{array}$ & $12 \cdot 2$ \\
\hline
\end{tabular}

* Values are mean \pm s.e.m.

$\dagger$ Based on dilutions used for assay of unconjugated oestrogens.

$\ddagger$ Expressed as Coefficient of Variation.

$\S$ Number of determinations.

$\uparrow$ Number of assays. 


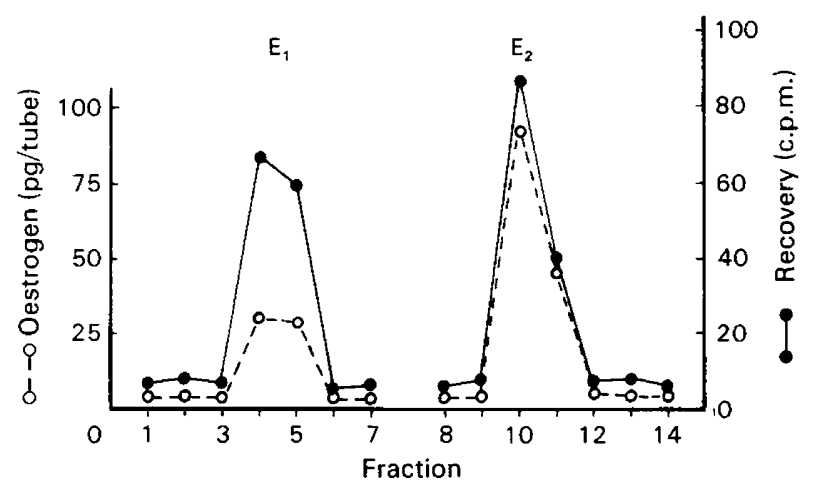

Text-fig. 1. Celite column co-chromatography of oestrone $\left(E_{1}\right)$ and oestradiol-17 $7\left(E_{2}\right)$ in marmoset urine. Oestrogen immunoreactivity is compared with recovery of pure tritiated hormone in $0.5 \mathrm{ml}$ fractions across the entire eluate taken for assay ( $3.5 \mathrm{ml}$ for each hormone).

across the appropriate fractions at $0.5 \mathrm{ml}$ intervals. The elution patterns obtained were interpreted as indicating specific measurement of each oestrogen. Co-chromatography of oestrone and oestradiol in urine is shown in Text-fig. 1 as an example. The same procedure was applied to the assay for oestriol and to determinations in plasma.

The efficiency of the hydrolysis procedure was tested by hydrolysing standard preparations of oestrone sulphate and oestrone glucuronide diluted to contain quantities of oestrone (available for release by hydrolysis) of $500-31.25 \mathrm{ng} / \mathrm{ml}$ (doubling dilutions). Regression analysis of the actual value against the amount of unconjugated oestrone measured gave the equations $y=0.98 x-7 \cdot 1$ (oestrone sulphate) and $y=1.08 x-13$ (oestrone glucuronide) $(y=$ unconjugated oestrone measured; $x=$ amount of oestrone available for release by hydrolysis). The slopes and intercepts of the regression equations were not significantly different from 1 and 0 , respectively and regression coefficients were $>0.98$.

Continuous elution reverse-phase high-pressure liquid chromatography (HPLC) was also performed on selected aliquants of hydrolysed samples according to the procedure described by Hodges, Gulick, Czekala \& Lasley (1981). The HPLC column used was a $5.0 \times 250 \mathrm{~mm}$ Lichrosorb - RP-18 (HPLC Technology Ltd, Runcorn, U.K.) with acetonitrile (Fisons, HPLC Grade) : water $(40: 60 \mathrm{v} / \mathrm{v})$ as a solvent system. Oestrogen immunoreactivity in each fraction collected was measured using an oestriol trisuccinyl-directed antiserum (S 310/5, G. E. Abraham) which demonstrates cross-reactivity with several oestrogenic compounds (Hodges et al., 1981). The elution pattern of oestrone, oestradiol and oestriol was monitored by the addition of tracer amounts of pure tritiated hormone before extraction and chromatography.

\section{Creatinine determination}

The creatinine concentration of each urine sample was estimated to help compensate for collection errors resulting from fluid intake and output and variable periods of collection. The usefulness of creatinine measurement to index hormone levels in small volumes of urine has been demonstrated for several primate species (Hodges, Czekala \& Lasley, 1979; Czekala et al., 1981). Hormone levels are divided by the concentration of creatinine and thus recorded as mass $/ \mathrm{mg}$ creatinine. The procedure used here for the creatinine assay has been previously described by Brand (1981) and the interassay coefficient of variation, based on repeated estimations of a biological standard, was $<10 \%$.

\section{Gas chromatography and mass spectroscopy}

Ethanol $(0 \cdot 1 \mathrm{ml})$ containing the purified extract was added to $3 \mathrm{ml}$ sodium acetate buffer ( $\mathrm{pH}$ $5 \cdot 1,1.5 \mathrm{M}$ ) containing $150 \mathrm{ng}$ methoxyamine hydrochloride. After heating at $60^{\circ} \mathrm{C}$ for $30 \mathrm{~min}$, 
the solution was extracted with ether : ethylacetate $(1: 1 \mathrm{v} / \mathrm{v})$, washed and dried. The residue was rewashed and dried, dissolved in a small vial in bis(trimethyl silyl)trifluoroacetamide and heated at $60^{\circ} \mathrm{C}$ for $30 \mathrm{~min}$ to form the trimethylsilyl (TMS) ester. The derivatized extract was analysed by GCMS using a $1.83 \mathrm{~m} \times 2 \mathrm{~mm}$ i.d. column packed with $1 \%$ Dexsil 300 on Valaspher (Merck) $100 / 120$ mesh. The column was temperature programmed from 220 to $320^{\circ} \mathrm{C}$ with increments of $4^{\circ} \mathrm{C} / \mathrm{min}$ and the effluent was analysed by a VG 305 spectrometer at 1000 resolution. Transfer lines were maintained at $250^{\circ} \mathrm{C}$ and the source temperature was $260^{\circ} \mathrm{C}$. Helium was used as the carrier gas at a flow rate of $12 \mathrm{ml} / \mathrm{min}$. The GC trace was obtained from ion summation by the data system.

\section{Analysis of data}

Statistical analysis of the data was performed using the least square means procedure (Statistical Analysis System, 1979). The overall significance of changes in stage of pregnancy related variables (in plasma and urine) was examined by one-way analysis of variance (ANOVA). Duncan's multiple range test was then used to compare individual means ( $5 \%$ significance level). Mean values within each stage of pregnancy were compared using a Student's $t$ test ( $P$ values stated in text).

\section{Results}

Concentrations of total and unconjugated oestrone and oestradiol in the plasma of marmosets at three stages of pregnancy are shown in Table 2. The greatly elevated concentrations of total (i.e. conjugated and unconjugated) hormone show that most of the circulating oestrone and oestradiol exists in the conjugated form. Incremental changes in the concentration of total and unconjugated fractions of both hormones occurred during the course of pregnancy $(P<0.001$, ANOVA). Differences between successive stages were significant from early to mid-pregnancy for total oestrone and from mid- to late pregnancy for unconjugated oestrone. Differences in oestradiol concentrations (total and unconjugated) were significant between all successive stages of pregnancy.

Levels of unconjugated oestrone were consistently greater than corresponding values for unconjugated oestradiol during early and mid-pregnancy (mean oestrone :oestradiol ratios, $12 \cdot 2$ and 2.4 respectively) whereas the concentration ratio was reversed (mean oestrone :oestradiol ratio, 0.15$)$ during late pregnancy $(P<0.01)$. In contrast, concentrations of total oestrone

Table 2. Circulating concentrations of total and unconjugated oestrone and oestradiol at three stages of pregnancy in the marmoset

\begin{tabular}{|c|c|c|c|c|c|c|c|}
\hline \multirow{2}{*}{$\begin{array}{l}\text { Stage of } \\
\text { pregnancy } \\
\text { (days) }\end{array}$} & \multirow[b]{2}{*}{$\begin{array}{l}\text { No. of } \\
\text { animals }\end{array}$} & \multicolumn{3}{|c|}{ Oestrone (ng/ml) } & \multicolumn{3}{|c|}{ Oestradiol (ng/ml) } \\
\hline & & Total* & Unconjugated & $\begin{array}{l}\% \text { of } \\
\text { total† }\end{array}$ & Total ${ }^{*}$ & Unconjugated & $\begin{array}{l}\% \text { of } \\
\text { total } \dagger\end{array}$ \\
\hline Early $(7-10)$ & 5 & 185.7 & $2 \cdot 8$ & 1.6 & $13 \cdot 1$ & $0 \cdot 3$ & $2 \cdot 4$ \\
\hline \multirow[t]{2}{*}{ Middle (75-85) } & 4 & 928.8 & $\begin{array}{r} \pm 0.4 \\
3.4\end{array}$ & $\begin{array}{r} \pm 0.5 \\
0.5\end{array}$ & $\begin{array}{r} \pm 2.1 \\
37.8\end{array}$ & $\begin{aligned} \pm 0.1 \\
1.4\end{aligned}$ & 3.9 \\
\hline & & $\pm 87 \cdot 3$ & \pm 0.6 & $\pm 0 \cdot 2$ & $\pm 4 \cdot 0$ & $\pm 0 \cdot 1$ & \pm 0.7 \\
\hline \multirow[t]{2}{*}{ Late $(129-140)$} & 4 & $591 \cdot 3$ & 6.9 & 0.9 & 137.5 & $49 \cdot 4$ & 35.1 \\
\hline & & $\pm 120 \cdot 0$ & \pm 0.8 & $\pm 0 \cdot 3$ & $\pm 31 \cdot 7$ & $\pm 8 \cdot 7$ & $\pm 6 \cdot 2$ \\
\hline
\end{tabular}

Values are mean \pm s.e.m.

* Values for total hormone are after enzyme hydrolysis and represent conjugated plus unconjugated components.

$\dagger$ The proportion of the total concentration in the unconjugated form. 
exceeded those of total oestradiol at all stages sampled (mean oestrone :oestradiol ratios $15 \cdot 1$, early: $25 \cdot 5$, middle; $4 \cdot 4$, late). The percentage of total oestrone circulating in the unconjugated form remained low throughout pregnancy $(<2 \%)$ although values for mid-pregnancy were significantly lower than at the other two stages. Values for the percentage unconjugated oestradiol were also low during early and mid-pregnancy, but significantly elevated in late pregnancy. A greater proportion of total oestradiol was circulating in unconjugated form during mid- $(P<0.02)$ and late $(P<0.01)$ pregnancy compared with corresponding values for oestrone.

Concentrations of circulating oestriol are not given; the values were low and insufficient plasma was available for reliable measurement. In two hydrolysed samples from late pregnancy, however, total oestriol levels were 8.4 and $10 \cdot 1 \mathrm{ng} / \mathrm{ml}$.

At each stage of pregnancy, urinary levels of total oestradiol exceeded those of total oestrone (mean oestradiol :oestrone ratios were 2.7-2.9); oestriol values were lowest (Table 3). The output of each hormone changed significantly during the course of gestation $(P<0.05$, ANOVA). The values for total oestrone and oestradiol in mid- and late pregnancy were higher than corresponding values in early pregnancy; total oestriol changed significantly between mid- and late pregnancy. For unconjugated hormone, the only differences were between early and late pregnancy for oestradiol and between mid- and late pregnancy for oestriol. There was no significant difference in

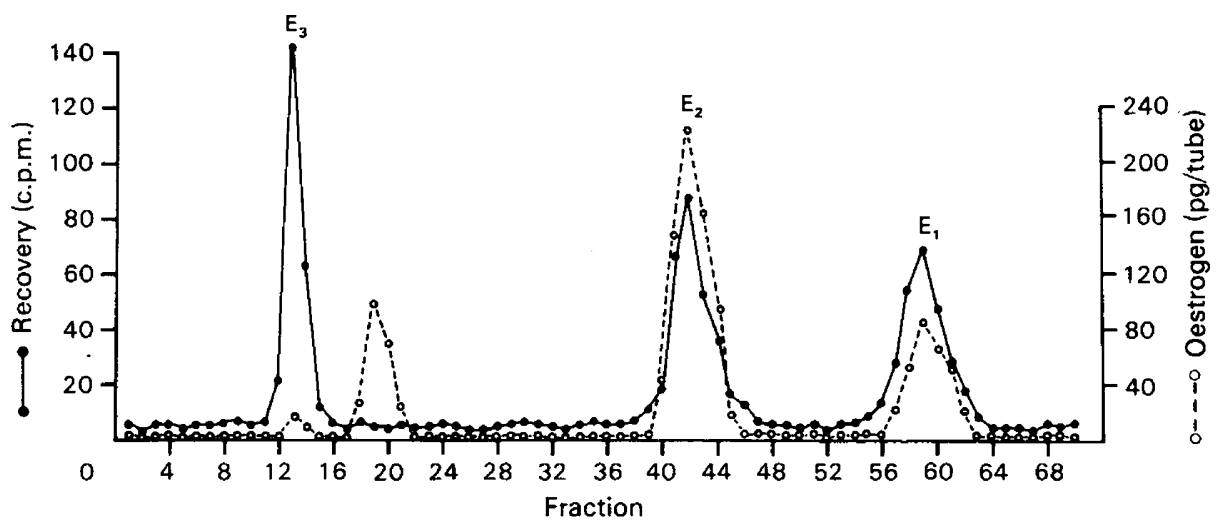

Text-fig. 2. High pressure liquid chromatographic separation of ether-extracted urine from a marmoset monkey at Day 9 of pregnancy. The profile of oestrogen immunoreactivity measured by a non-specific oestrogen antibody is compared with the recovery of $\left[{ }^{3} \mathrm{H}\right]$ oestrone $\left(\mathrm{E}_{1}\right)$, $\left[{ }^{3} \mathrm{H}\right.$ ]oestradiol-17ß $\left(\mathrm{E}_{2}\right)$ and $\left[{ }^{3} \mathrm{H}\right]$ oestriol $\left(\mathrm{E}_{3}\right)$.

Table 3. Levels of total and unconjugated oestrone, oestradiol and oestriol in the urine of marmosets at three stages of pregnancy

\begin{tabular}{|c|c|c|c|c|c|c|c|c|c|c|}
\hline \multirow{2}{*}{$\begin{array}{l}\text { Stage of } \\
\text { pregnancy } \\
\text { (days) }\end{array}$} & \multirow[b]{2}{*}{$\begin{array}{l}\text { No. of } \\
\text { animals }\end{array}$} & \multicolumn{3}{|c|}{ Oestrone $(\mu \mathrm{g} / \mathrm{mg} \mathrm{Cr})$} & \multicolumn{3}{|c|}{ Oestradiol $-17 \beta(\mu \mathrm{g} / \mathrm{mg} \mathrm{Cr})$} & \multicolumn{3}{|c|}{ Oestriol ( $\mu \mathrm{g} / \mathrm{mg} \mathrm{Cr})$} \\
\hline & & Total $^{*}$ & $\begin{array}{l}\text { Unconju- } \\
\text { gated }\end{array}$ & $\begin{array}{l}\% \text { of } \\
\text { total } \dagger\end{array}$ & Total ${ }^{*}$ & $\begin{array}{l}\text { Unconju- } \\
\text { gated }\end{array}$ & $\begin{array}{l}\% \text { of } \\
\text { total }+\end{array}$ & Total $^{*}$ & $\begin{array}{l}\text { Unconju- } \\
\text { gated }\end{array}$ & $\begin{array}{l}\% \text { of } \\
\text { totalf }\end{array}$ \\
\hline \multirow[t]{2}{*}{ Early $(7-10)$} & 5 & $8 \cdot 8$ & $0 \cdot 3$ & $3 \cdot 2$ & $25 \cdot 4$ & 0.9 & 3.8 & $0 \cdot 3$ & 0.02 & $8 \cdot 4$ \\
\hline & & \pm 1.8 & $\pm 0 \cdot 2$ & $\pm 1 \cdot 0$ & $\pm 6 \cdot 1$ & $\pm 0 \cdot 3$ & $\pm 1 \cdot 5$ & \pm 0.06 & \pm 0.01 & $\pm 3 \cdot 0$ \\
\hline \multirow[t]{2}{*}{ Middle (75-85) } & 4 & $31 \cdot 7$ & $1 \cdot 3$ & 6.9 & 83.6 & 2.7 & 3.9 & $3 \cdot 3$ & 0.05 & $2 \cdot 6$ \\
\hline & & $\pm 10 \cdot 1$ & $\pm 0 \cdot 3$ & \pm 2.9 & $\pm 19 \cdot 2$ & \pm 0.8 & $\pm 1 \cdot 4$ & $\pm 1 \cdot 0$ & \pm 0.01 & $\pm 1 \cdot 2$ \\
\hline \multirow[t]{2}{*}{ Late $(129-140)$} & 4 & \pm 27.6 & $2 \cdot 2$ & 8.9 & $74 \cdot 3$ & $6 \cdot 1$ & $7 \cdot 4$ & $7 \cdot 8$ & $0 \cdot 3$ & $3 \cdot 8$ \\
\hline & & $\pm 5 \cdot 4$ & $\pm 0 \cdot 8$ & $\pm 4 \cdot 0$ & $\pm 10 \cdot 1$ & $\pm 2 \cdot 0$ & $\pm 2 \cdot 2$ & $\pm 2 \cdot 2$ & $\pm 0 \cdot 1$ & $\pm 1 \cdot 3$ \\
\hline
\end{tabular}

Values are mean \pm s.e.m,

* After enzyme hydrolysis, and represent conjugated plus unconjugated components.

$\dagger$ The proportion of the total concentration in the unconjugated form. 
figures for unconjugated hormone as a percentage of the total between hormones $(P<0.05)$ or between stages of pregnancy.

The presence of immunoreactive oestrogens other than oestrone, oestradiol and oestriol in urine and plasma was also examined. Separation of component oestrogen immunoreactivity by HPLC is exemplified in Text-fig. 2 for a hydrolysed urine sample from early pregnancy. As expected, the most abundant immunoreactive oestrogen corresponded to the elution position of pure tritiated oestradiol. Oestrone and oestriol were also present but there was considerable additional immunoreactivity in fractions $18-20$, slightly after the elution position of oestriol. Immunoreactivity associated with the same fractions was abundant in urine samples from middle and late pregnancy and also in hydrolysed plasma, but at lower levels relative to those of oestrone and oestradiol-17 $\beta$.
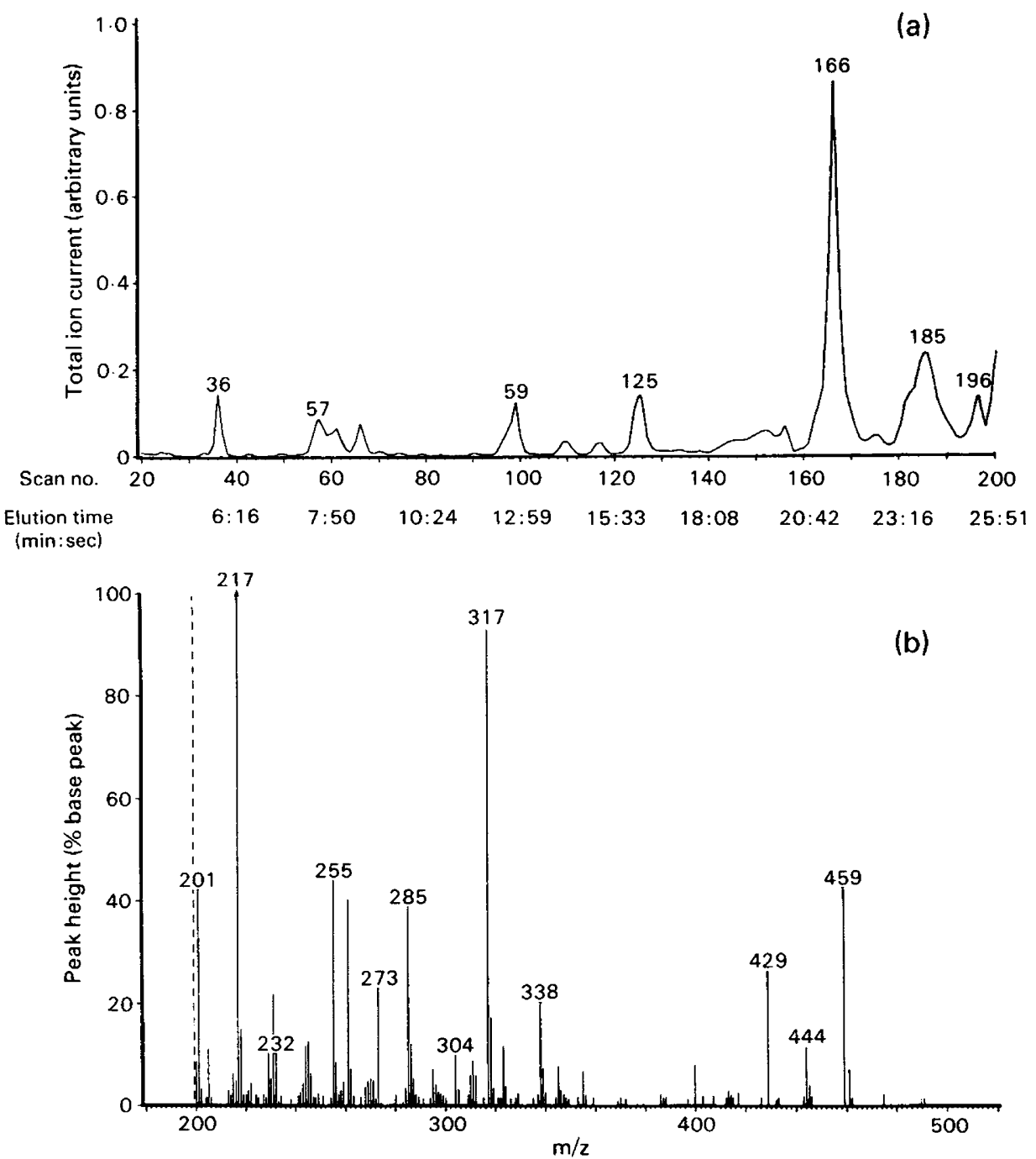

Text-fig. 3. The gas chromatographic trace (g.l.c.) (a) and mass spectrum (b) of the methoxyamine trimethylsilyl derivative of the extract of fractions 18-20 eluted from highpressure liquid chromatography (HPLC). The HPLC separation was performed on etherextracted urine from Day 9 of pregnancy (see Text-fig. 2). The mass spectrum of the g.l.c. peak at scan no. 166 in (a) is given in (b). 
The HPLC retention time of the unidentified substance in early pregnancy urine was shown to be the same as that of pure $16 \alpha$-hydroxyoestrone. Under the experimental conditions imposed, both substances had an $R_{\mathrm{F}}$ value of 1.5 relative to oestriol. Subsequent GC-MS analysis of the MO-TMS ether derivative of the steroid(s) isolated in fractions 18-20 from HPLC is illustrated in Text-fig. 3. The GC trace showed a well defined peak at 166 corresponding to that of standard $16 \alpha$-hydroxyoestrone as the methyloxime TMS derivative. The mass spectrum was compatible with that of $16 \alpha-$ hydroxyoestrone, the molecular ion (M) was at $\mathrm{m} / \mathrm{z} 459$ and peaks were observed at M-31 ( $\mathrm{m} / \mathrm{z} 429)$ corresponding to the loss of $-\mathrm{OMe}$ from the oxime and at $\mathrm{M}-31+90(\mathrm{~m} / \mathrm{z} 338)$ corresponding to the further loss of trimethyl silanyl. The peak at $\mathrm{m} / \mathrm{z} 317 \mathrm{did}$ not occur in the mass spectrum of standard 16 $\alpha$-hydroxyoestrone and may have arisen from the mass spectrum of a co-eluting compound.

\section{Discussion}

This paper reports the measurement of circulating and urinary oestrogens at three stages of pregnancy in the marmoset monkey. The plasma concentrations of unconjugated oestrone and oestradiol described here are similar to, but slightly lower than, those reported previously (Chambers \& Hearn, 1979; P. L. Chambers, pers. comm.). This discrepancy probably derives from differences in assay procedure, although the small number of animals used in the present study may be contributory. Chambers \& Hearn (1979) reported that concentrations of unconjugated oestrone and oestradiol during late pregnancy in the marmoset were high relative to those in various other primate species and in man. The present findings substantiate this and extend the comparison to early pregnancy in which concentrations of oestradiol and particularly oestrone are also higher than in other primates, including man (Tulchinsky \& Hobel, 1973), rhesus monkey (Walsh, Wolf, Meyer \& Robinson, 1979), chimpanzee (Reyes, Winter, Faiman \& Hobson, 1975) and baboon (Hendrickx \& Enders, 1980).

Few data on the concentrations of total oestrone and oestradiol in other primate species are available for comparison with the marmoset. Loriaux, Ruder, Knab \& Lipsett (1972) and Smith \& Hagerman (1965) reported concentrations of oestrone sulphate of approximately $70 \mathrm{ng} / \mathrm{ml} \mathrm{during}$ late pregnancy in women, whilst concentrations of total oestradiol at the same gestational stage were 20-30 ng/ml (Smith \& Hagerman, 1965). Similarly, in the marmoset, total oestrone predominates over total oestradiol, but the absolute levels of both hormones are much higher. Production of high levels of steroids is characteristic of many New World monkeys but is without explanation. Koering (1974) reported that the ovaries of the New World primates contain an abundance of luteal tissue. Whilst this may contribute to high steroid levels during the luteal phase and early pregnancy, the ovarian contribution to oestrogen concentrations in later stages of pregnancy is relatively small (Chambers, 1981).

Comparison of total and unconjugated levels of oestrone and oestradiol during pregnancy in the marmoset indicates a lower percentage of unconjugated hormone than in women (Loriaux et al., 1972; Adlercreutz, Tikkanen \& Hunneman, 1974). There is also a marked change in the proportion of conjugation of oestrone and oestradiol during pregnancy in the marmoset in that the concentration ratio of unconjugated oestrone : oestradiol reverses during pregnancy (Chambers \& Hearn, 1979; present results) despite the continuing predominance of oestrone when measured as total hormone. The rapid increase in unconjugated oestradiol during the last 8 weeks of pregnancy in the marmoset (Chambers \& Hearn, 1979) therefore appears to be related to a change in the degree of conjugation of the hormone as well as to an increase in production.

The predominant form of oestrogen detected in the urine at each stage of pregnancy was oestradiol, thus confirming previous observations by Shackleton (1974) and Lunn (1978). This is in contrast to other South American species (Hodges et al., 1981) and Old World monkeys which excrete mainly oestrone and to the apes and man for which oestriol is the most abundant urinary metabolite (see Ryan \& Hopper, 1974, for review). As an explanation for this Shackleton (1974) 
proposed that in the marmoset oestradiol was excreted largely unmetabolized. The present data, however, indirectly suggest that urinary oestradiol may be derived from circulating oestrone and that some oestrone may also be excreted unmetabolized. In women, metabolism of oestrogens is largely oxidative in nature (Fishman, Bradlow \& Gallagher, 1960). Oestrone and oestradiol are interconvertible, but the initial and predominant direction of metabolism is from oestradiol to oestrone, with conversion of oestrone to oestradiol being a slower and secondary reaction. It is suggested that the preferred direction of metabolism of oestrogens in the marmoset is from oestrone to oestradiol but there is no direct evidence for this speculation. There are no similar data from other non-human primates for comparison.

Although concentrations of oestriol remained low relative to those of oestrone and oestradiol, there was 25-fold difference between early and late pregnancy values. Increasing concentrations of oestriol during pregnancy in women (and probably also in apes) reflect placental metabolism of fetal 16 $\alpha$-dehydroepiandrosterone sulphate (Siiteri \& MacDonald, 1963; Diczfalusy, 1969). In view of the low circulating levels of oestriol during pregnancy reported here, it is more likely that in the marmoset this hormone is derived from peripheral metabolism of oestrone before excretion rather than from any substantial feto-placental production. The existence of feto-placental oestrogen production in New World monkeys remains to be demonstrated although the marmoset placenta can aromatize androstenedione to oestrone in vitro (Ryan, Benirschke \& Smith, 1961).

In agreement with Shackleton's earlier finding (1974) the present data suggest that $16 \alpha-$ hydroxyoestrone is an abundant urinary oestrogen metabolite during pregnancy in the marmoset. The amount of 'additional' immunoreactivity relative to oestrone, oestradiol and oestriol in a single urine sample is shown in Text-fig. 2 but requires some adjustment because $16 \alpha$-hydroxyoestrone has a lower cross-reactivity $(\sim 65 \%)$ with the non-specific antibody used compared with that of the three classical oestrogens (Hodges et al., 1981). Since, however, the gas chromatography-mass spectroscopy data presented here do not show conclusively that the immunoreactivity in the HPLC fractions 18-20 can be fully accounted for by 16 $\alpha$-hydroxyoestrone, absolute values were not available but are being investigated.

High concentrations of $16 \alpha$-hydroxyoestrone have been reported in the plasma (Adlercreutz et al., 1974) and in urine (Adessi, Goutte-Coussieu, Nhuan \& Jayle, 1976) of women during late pregnancy. The physiological significance of this hormone is not known although it is biologically active (Fishman \& Martucci, 1980) and in man is an intermediate in the biotransformation of oestrone to oestriol (Brown \& Marrian, 1957). In the marmoset, 16 $\alpha$-hydroxylation also appears to be an important pathway for oestrogen metabolism but there is relatively little further metabolism to oestriol.

The present study provides an initial account of circulating and urinary oestrogens during pregnancy in the marmoset monkey. Although there are areas of similarity with other non-human primates and man, the high circulating concentrations of conjugated oestrogens and the predominance of oestradiol in urine are unusual. The significance of these findings in relation to the control of pregnancy in the marmoset remains to be determined.

We thank Dr D. H. Abbott for help with statistical analysis; Dr S. A. K. Eastman for assistance with collection of urine; Mrs B. Murrill for care and maintenance of the animals; HPLC Technology for their gift of a Lichrosorb RP 18 column; and the World Health Organization for supplying antiserum and standards for the oestradiol-17\% assay.

This work was supported by an M.R.C. Programme Grant to Professor J. P. Hearn and by a Grant from the A.B.R.C. to the Institute of Zoology.

\section{References}

Abraham, G.E., Tulchinsky, D. \& Korenman, S.G. (1970) Chromatographic purification of estradiol-17 $\beta$ for use in radioligand assay. Biochem. Med. 3, 365-368. Adessi, G.L., Goutte-Coussieu, C., Nhuan, T.Q. \& Jayle, Downloaded from Bioscientifica.com at 04/26/2023 08:25:04AM 
M.F. (1976) Variations of the excretion curves of seven urinary oestrogens during late pregnancy. Eur. J. Obstet. Gynec. Reprod. Biol. 6, 319-324.

Adlercreutz, H., Tikkanen, M.J. \& Hunneman, D.H. (1974) Mass fragmentographic determination of eleven estrogens in the body fluids of pregnant and non pregnant subjects. J. Steroid Biochem. 5, 211217.

Anderson, D.C., Hopper, B.R., Lasley, B.L. \& Yen, S.S.C. (1976) A simple method for the assay of eight steroids in small volumes of plasma. Steroids 28, 179-196.

Brand, H.M. (1981) Urinary oestrogen excretion in the female cotton-topped tamarin (Saguinus oedipus oedipus). J. Reprod. Fert. 62, 467-473.

Brown, J.B. \& Marrian, G.F. (1957) The metabolic reduction of $16 \alpha$-hydroxyoestrone to oestriol in man. J. Endocr. 15, 307-309.

Chambers, P.L. (1981) The endocrinology of pregnancy in the marmoset monkey, Callithrix jacchus. Ph.D. thesis, University of Edinburgh.

Chambers, P.L. \& Hearn J.P. (1979) Peripheral plasma levels of progesterone, oestradiol-17 $\beta$, oestrone, androstenedione and chorionic gonadotrophin during pregnancy in the marmoset monkey, Callithrix jacchus. J. Reprod. Fert. 56, 23-32.

Czekala, N.M., Hodges, J.K. \& Lasley, B.L. (1981) Pregnancy monitoring in diverse primate species by estrogen and bioactive luteinizing hormone determinations in small volumes of urine. J. med. Primatol. 10, $1-15$

Diczfalusy, E. (1969) Steroid metabolism in the foetoplacental unit. In The Foeto-Placental Unit, pp. 6580. Eds A. Pecile \& C. Finzi. Excerpta Medica, Amsterdam.

Fishman, J. \& Martucci, C. (1980) Biological properties of 16 -hydroxyestrone: implications in estrogen physiology and pathophysiology. J. clin. Endocr. Metab. 51, 611-615.

Fishman, J., Bradlow, H.L. \& Gallagher, T.F. (1960) Oxidative metabolism of estradiol. J. biol. Chem. 235, 3104-3107.

Hendrickx, A.G. \& Enders, A.C. (1980) Implantation in non human primates: II. Endocrinology. In Non Human Primate Models for Study of Human Reproduction, pp. 109-115. Ed. T. C. Anand Kumar. Karger, Basel.

Hodges, J.K., Czekala, N.M. \& Lasley, B.L. (1979) Estrogen and luteinizing hormone secretion in diverse primate species from simplified urinary analysis. $J$. med. Primatol. 8, 349-364.
Hodges, J.K., Gulick, B.A., Czekala, N.M. \& Lasley, B.L. (1981) Comparison of urinary oestrogen excretion in South American primates. J. Reprod. Fert. 61, 83-90.

Koering, M.J. (1974) Comparative morphology of the primate ovary. Contrib. Primat. 3, 38-81.

Loriaux, D.L., Ruder, H.J., Knab, D.R. \& Lipsett, M.B. (1972) Estrone sulfate, estrone, estradiol and estriol plasma levels in human pregnancy. J. clin. Endocr. Metab. 35, 887-891.

Lunn, S.F. (1978) Urinary oestrogen excretion in the common marmoset (Callithrix jacchus). In Biology and Behaviour of Marmosets, pp. 67-74. Eds $\mathbf{H}$. Rothe, H. J. Walters \& J. P. Hearn. Eigenverlag Rothe, Göttingen.

Reyes, F.I., Winter, J.S.D., Faiman, C. \& Hobson, W.C. (1975) Serial serum levels of gonadotropin, prolactin and sex steroids in the non-pregnant and pregnant chimpanzee. Endocrinology 96, 1447-1455.

Ryan, K.J. \& Hopper, B.R. (1974) Placental biosynthesis and metabolism of steroid hormones in primates. Contrib. Primat. 3, 258-283.

Ryan, K.J., Benirschke, K. \& Smith, O.W. (1961) Conversion of androstenedione-4- $\mathrm{C}^{14}$ to estrone by the marmoset placenta. Endocrinology 69, 613-618.

Shackleton, C.H.P. (1974) Progesterone and oestrogen metabolism in the pregnant marmoset, Callithrix jacchus. J. Steroid Biochem. 15, 597-600.

Siiteri, P.K. \& MacDonald, P.C. (1963) The utilization of circulating dehydroisoandrosterone sulfate estrogen synthesis during human pregnancy. Steroids 2, 713718 .

Smith, O.W. \& Hagerman, D.D. (1965) Quantitative estimation of estrogen conjugates in late pregnancy plasma. J. clin. Endocr. Metab. 25, 732-741.

Tulchinsky, D. \& Abraham, G.E. (1971) Radioimmunoassay of plasma estriol. J. clin. Endocr. Metab. 33, 775-782.

Tulchinsky, D. \& Hobel, C.J. (1973) Plasma human chorionic gonadotropin, estrone, estradiol, estriol, progesterone and 17-hydroxyprogesterone in human pregnancy. III. Early normal pregnancy. Am. J. Obstet. Gynec. 117, 884-893.

Walsh, S.W., Wolf, R.C., Meyer, R.K. \& Robinson, J.A. (1979) Estrogens in the uteroovarian, uterine and peripheral plasma in pregnant rhesus monkeys. Biol. Reprod. 20, 606-610.

Received 22 April 1982 